Br Heart J 1987;57:593

\title{
Correspondence
}

\section{Influence of profuse sweating on systolic time intervals}

Sir,

We compliment Ishikawa and Ishikawa (1986;56: 176-8) on their interesting data, but we have some reservations about their conclusions and interpretation of the haemodynamic mechanisms.

They clearly define the influence of a sauna (and presumably profuse sweating) on systolic time intervals as producing a prolonged pre-ejection period and pre-ejection period divided by ejection time, a shortened ejection time, and an unchanged electromechanical systole. Heart rate and blood pressure were unchanged and haematocrit and body weight decreased. Ishikawa and Ishikawa conclude "...systolic time intervals measured after profuse sweating can give a false impression of cardiac function". In contrast, we believe that they gave a true impression and that cardiac function really was reduced after sweating.

A prolonged pre-ejection period, especially with a shortened ejection time, is an acknowledged hallmark of reduced cardiac performance (by any mechanism). Heart rate was unchanged and, therefore, was not contributory. Since blood pressure was unchanged, afterload probably was stable. Although Ishikawa and Ishikawa did not investigate preload (for example by echocardiography), the acute decreases in haematocrit and body weight indicate reduced blood volume consistent with preload reduction. Indeed, the changes in systolic time intervals are identical with those seen after preload reduction ${ }^{12}$ and can be explained by a leftward shift of the Frank-Starling curve. Finally, electromechanical systole $\left(\mathrm{QII} \mathrm{I}_{\mathrm{c}}\right)$, which is very sensitive to changes in contractility, ${ }^{34}$ was stable.

Thus we conclude that cardiac function was indeed altered by the sauna and that this was probably the result of preload reduction rather than reduced contractility. We recommend that loaddependent measurements, such as the pre-ejection period and its ratio to ejection time, are best interpreted after taking into account simultaneously measured information about loading conditions.

Gustav G Belz,

Institute for Cardiovascular Therapy,

Alwinenstrasse 16,

6200 Wiesbaden,

Federal Republic of Germany.

David H Spodick,

Division of Cardiology,

St Vincent Hospital,

University of Massachusetts,

Worcester, MA 01604,

USA.

\section{References}

1 Buch J, Egeblad H, Hansen PB, Kjaergård H, Waldorff $S$, Steiness E. Correlation between changes in systolic time intervals and left ventricular end-diastolic diameter after preload reduction. Non-invasive monitoring of pharmacological intervention. Br Heart $J$ 1980;44:668-71.

2 De La Paz LR, Kerigan AT, Koch GG, Kolman WA, Spodick DH. Erythrityl tetranitrate: changes consistent with sustained preload reduction. Am J Med Sci 1979;277:173-8.

3 Lewis RP, Rittgers SE, Forester WF, Boudoulas H. A critical review of the systolic time intervals. Circulation 1977;56:146-58.

4 Stern HC, Matthews JH, Belz GG. Influence of dihydralazine induced afterload reduction on systolic time intervals and echocardiography in healthy subjects. Br Heart J 1984;52:435-9. 